\title{
Changes in Social Behavior Over Time During the COVID-19 Pandemic
}

\author{
Megan M. Sheehan ${ }^{1}$, Elizabeth Pfoh ${ }^{1}$, Sidra L. Speaker ${ }^{1}$, Michael Rothberg ${ }^{1}$ \\ 1. Center for Value-Based Care Research, Cleveland Clinic, Cleveland, USA
}

Corresponding author: Megan M. Sheehan, sheeham3@ccf.org

\begin{abstract}
Public health recommendations aimed at limiting the spread of SARS-CoV-2 have encouraged social distancing and masks as economies across the United States re-open. Understanding adherence to these guidelines will inform further efforts to reduce transmission. In this repeated cross-sectional survey study, we describe changes in social behavior in Ohio during periods of declining and rising cases. While essential activities remained consistent over time, more individuals attended gatherings of 10 or more people as cases rose, particularly in the 18-29 age group. A majority of individuals wore masks. It appears necessary to continue limiting gatherings and encourage mask-wearing, particularly among younger groups.
\end{abstract}

Categories: Preventive Medicine, Infectious Disease, Public Health

Keywords: covid-19, social distancing, public health

\section{Introduction}

In March 2020, Ohio and other states closed schools, workplaces, and gathering spots to limit the transmission of SARS-CoV-2. Experience from prior pandemics and containment strategy modeling contributed to the development and implementation of these interventions [1-2]. Early studies from the current pandemic support their efficacy - a population-based cohort study from China showed that social distancing measures, home isolation, and improved medical resources were associated with a reduction in cases [3]. In a study of four metropolitan areas throughout the United States, community mitigation policies, including social distancing and personal protective measures, also correlated with declining cases [4]. A study of patient adherence to public health recommendations in three countries found that government response efforts positively influenced adherence [5]. In Ohio, gatherings of more than 10 people were largely prohibited, and the adoption of social distancing and cloth face masks was encouraged to prevent the rapid spread of the virus [6]. As states flattened the curve of new transmissions, they began to reopen.

Unfortunately, as restrictions lifted, cases have increased [7]. Understanding to what extent individuals adhered to public health recommendations during reopening can help inform current efforts to shape public behavior and reduce transmission. In this study, we describe social behavior in Ohio early in the re-opening phase, when cases were still declining, and then afterward as cases rose.

Received 09/02/2020

Review began 09/14/2020 Review ended 10/01/2020 Published 10/01/2020

\section{๑) Copyright 2020}

Sheehan et al. This is an open access article distributed under the terms of the Creative Commons Attribution License CC-BY 4.0., which permits unrestricted use, distribution, and reproduction in any medium, provided the original author and source are credited.

\section{Materials And Methods}

This repeated cross-sectional study surveyed adults who were seen at a large integrated health system in Ohio in the past 12 months and who are active on MyChart. MyChart is a personal health record (patient portal) that enables patients to access their health information online via their phone, tablet, or computer. We sent the survey via MyChart because it enabled us to identify a large population of patients and securely send a survey. We excluded patients who tested positive for SARS-COV2 before the survey. The survey was sent to 9,097 patients who had a visit to an internal medicine or family medicine physician in the prior year. Patients were sent a 14-question survey via MyChart about social distancing and hygiene behaviors in the past seven days [8]. The survey included questions about hand-washing, mask-wearing, essential activities, such as grocery shopping and seeking healthcare, and social activities such as attending public or private gatherings. The survey also asked about chronic health problems such as lung disease, immunosuppression, and high blood pressure. It was developed based on expert opinion and prior surveys [9-10]. It was pilottested with 10 individuals. After testing, we changed the survey window to ask about behaviors in the last seven days, as people had trouble recalling activities for 14 days. The survey was sent out in seven waves from May 19 to July 24. After an initial lock-down period, Ohio began to reopen on April 30; daily cases bottomed on June 15 and then rose substantially; mask-wearing was mandated on July 23 (Figure 1) [11]. 


\section{Cureus}

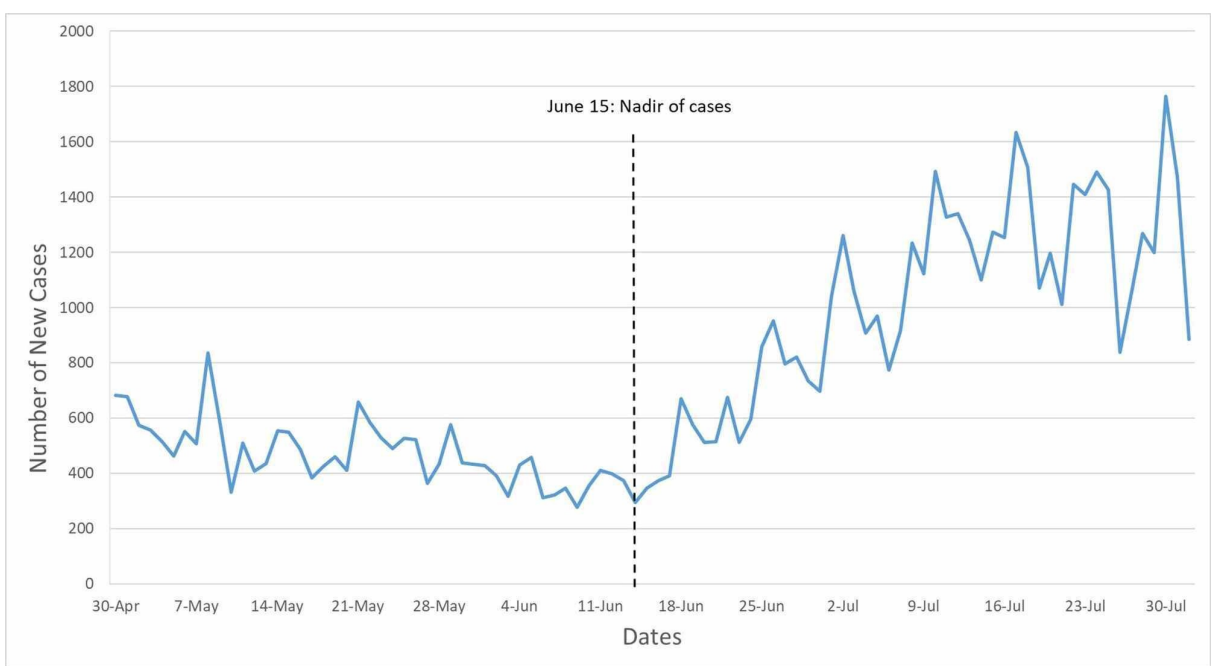

FIGURE 1: COVID-19 cases in Ohio

Survey responses before and after the June 15 nadir were compared using student's t-tests for numeric variables and the Pearson chi-square or Fisher's exact tests for categorical variables. Secondarily, we compared respondents who stated they "always wore masks" to respondents who wore masks less often to identify if there were other differences in public health behaviors. All statistical tests were two-tailed with a significance threshold of 0.05. Analyses were conducted using R v.4.02. This work was approved by the Cleveland Clinic Institutional Review Board. An earlier version of this article was published as a preprint [12].

\section{Results}

A total of 654 individuals responded (7\% response rate) and were similar in age and sex before and after the June 15 nadir in daily cases. The majority of respondents were female (69\%) and the median age was 56 years. A majority of respondents wore a mask outside the home, $53 \%$ before and $64 \%$ after the nadir $(\mathrm{p}=$ 0.008 ). More respondents attended a gathering of 10 or more people after the nadir ( $19 \%$ versus $11 \%, p=0.01$ ) (Table 1). Those who attended a large gathering were less likely to wear masks ( $34 \%$ versus $66 \%$, $\mathrm{p}<0.001$ ).

\begin{tabular}{|c|c|c|c|}
\hline Survey Question & Pre-nadir $\mathrm{n}=214 \mathrm{~N}(\%)$ & Post-nadir n=440 N (\%) & p-value \\
\hline Close contact with someone who has COVID* & 1 (0.5) & $5(1)$ & 0.67 \\
\hline \multicolumn{4}{|l|}{ Demographics and health status } \\
\hline Age & $54(37,66)$ & $56(36,70)$ & 0.53 \\
\hline Gender - Female & $139(66)$ & $304(70)$ & 0.33 \\
\hline Number of people living at home & $2(2,4)$ & $2(2,3)$ & 0.41 \\
\hline Someone at home had URI symptoms in the past week & $7(3)$ & $20(5)$ & 0.54 \\
\hline Someone at home provides patient care & 24 (11) & $38(9)$ & 0.35 \\
\hline Been placed in isolation or quarantine & 9(4) & $8(2)$ & 0.11 \\
\hline Lung disease (e.g. asthma, chronic obstructive pulmonary disease) & 30 (14) & $61(14)$ & 1 \\
\hline Immune suppression & $20(9)$ & $32(7)$ & 0.44 \\
\hline High blood pressure & $65(30)$ & $127(29)$ & 0.76 \\
\hline \multicolumn{4}{|l|}{ Social activities } \\
\hline Gone to a friend, neighbor, or relative's residence & $108(51)$ & $211(48)$ & 0.64 \\
\hline Attended a large gathering (10+ people) & $23(11)$ & 84 (19) & 0.01 \\
\hline Gone out to a bar, club, or other place where people gather & 26 (12) & 66 (15) & 0.38 \\
\hline ctivities of daily living & & & \\
\hline
\end{tabular}




\section{Cureus}

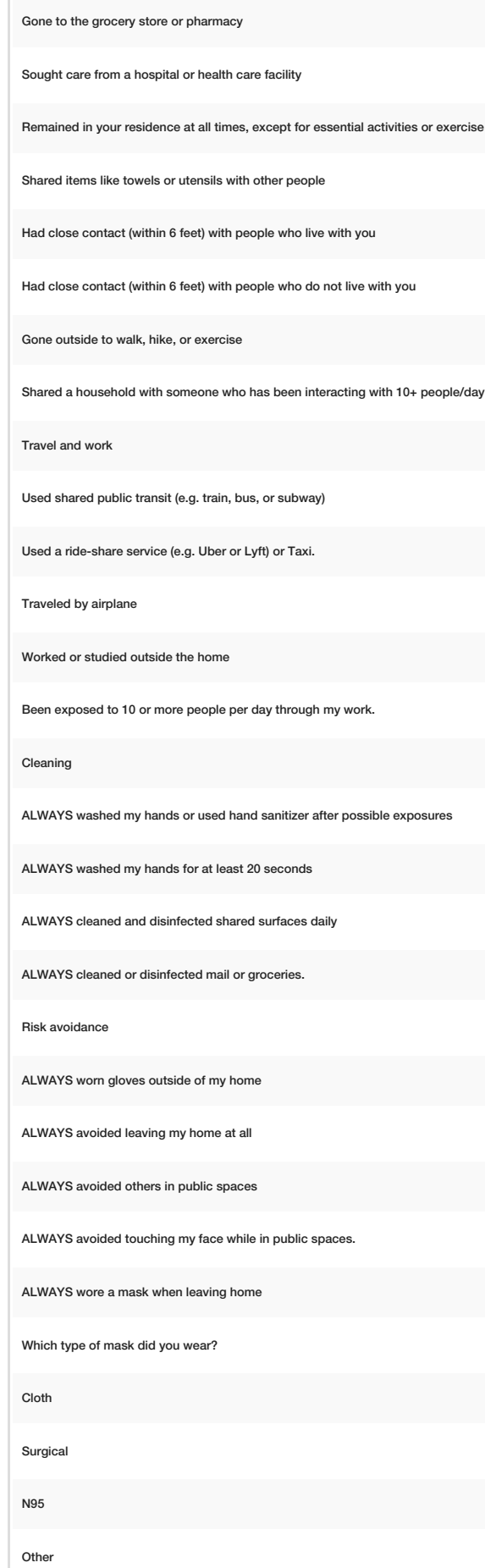

\section{TABLE 1: Survey responses before and after the nadir of cases*}

*Survey responses were grouped into before the nadir of COVID-19 cases in Ohio (June 15, 2020) and after. Besides the demographic and health status questions, the survey asked respondents to use a seven-day look-back period for their activities. Values are given as number (\%) or median (interquartile range) for age and number of people living at home. 


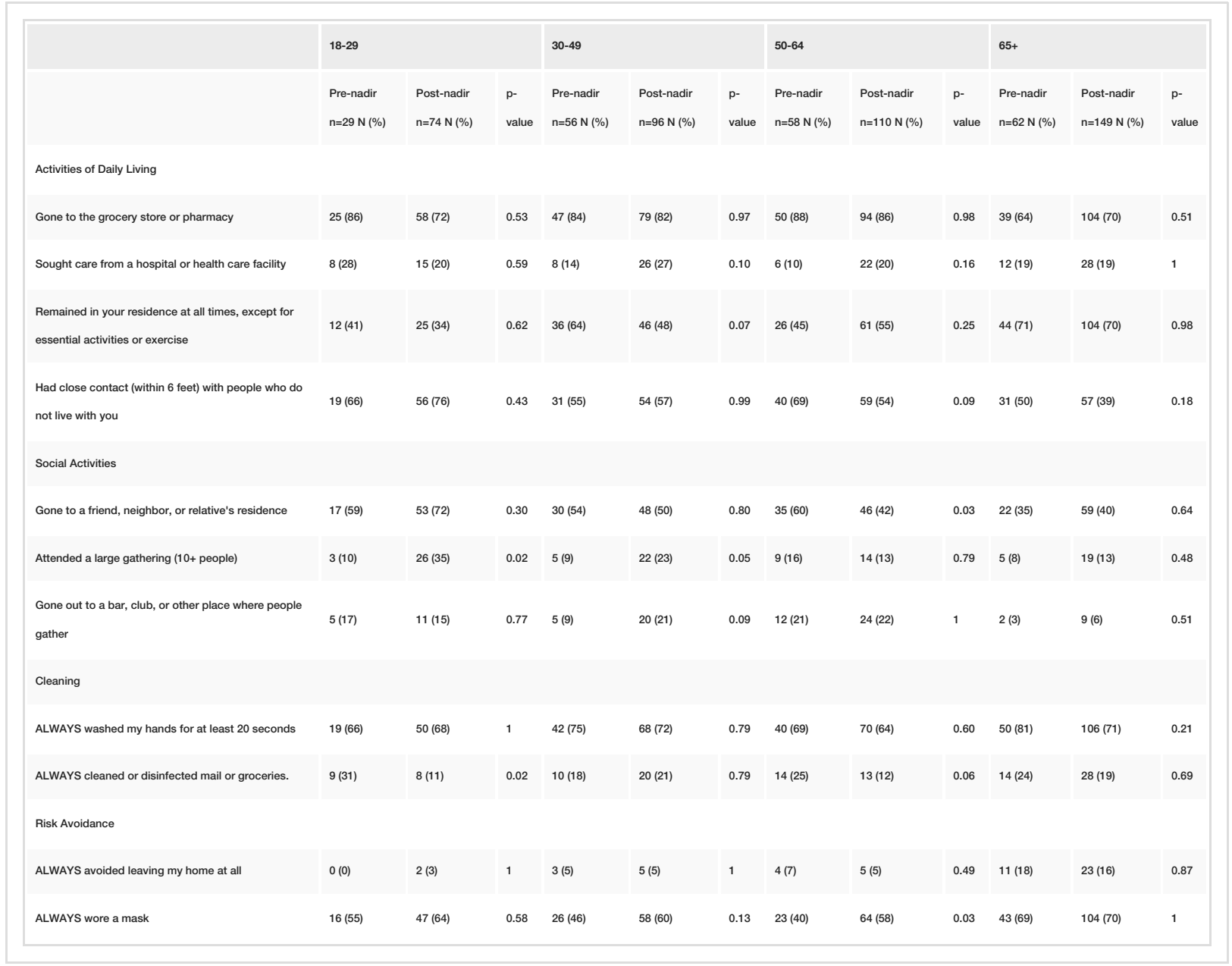

TABLE 2: Activities of daily living, social activities, and risk avoidance before and after the nadir of cases by age group*

*Survey responses were grouped into before the nadir of COVID-19 cases in Ohio (June 15, 2020) and after. Besides the demographic and health status questions, the survey asked respondents to use a seven-day look-back period for their activities.

Respondents who always wore masks were more often female $(75 \%$ versus $59 \%, \mathrm{p}<0.001)$, and they practiced other protective behaviors. Those who always masked washed hands more frequently after possible exposures ( $78 \%$ versus $46 \%, \mathrm{p}<0.001$ ) and avoided others in public spaces ( $51 \%$ versus $22 \%, \mathrm{p}<0.001$ ). Respondents who did not always mask outside their home were more likely to visit a friend or neighbor's residence $(58 \%$ versus $43 \%, \mathrm{p}<0.001)$ or a bar or club $(24 \%$ versus $8 \%, \mathrm{p}<0.001)$ and have close contact with people that they did not live with $(70 \%$ versus $45 \%, \mathrm{p}<0.001)$.

\section{Discussion}

In this repeated cross-sectional survey study, we found an increasing percentage of individuals attended large gatherings as cases were rising in Ohio, compared to a period of declining cases. Increased socialization was most apparent among 18-29-year-olds, possibly illustrating 'caution fatigue' amongst those at the lowest risk of dying from COVID-19 [13]. This behavior has been reported anecdotally in the lay press but has not been previously documented. As colleges begin to reopen around the country, there are growing concerns about potential outbreaks on campuses. Our study adds to these concerns, as we found that this age group is most likely to disregard public health recommendations and gather in large groups.

While the majority of respondents, especially those over 65 years, used masks, individuals who attended gatherings did so less consistently. As our survey was distributed prior to mask mandates in Ohio, we did not capture the impact of these mandates on public behavior. Essential activities and sanitization practices remained largely consistent across time and age groups, although the percentage of respondents who routinely disinfected groceries or mail decreased over time. This may reflect increased awareness of public health messaging, as the Centers for Disease Control and Prevention (CDC) states there is a very low risk of spread from these objects [14]. The majority of respondents practiced hand-washing after possible exposures, suggesting that this may have become a habit that will persist throughout the pandemic and 
afterward.

There have been concerns that those who wear face coverings may be less likely to adopt other protective measures due to risk compensation. Our study suggests the opposite, that those who wear masks are more likely to follow all public health recommendations. Conversely, we found that those who did not wear masks were less likely to adhere to social distancing recommendations, which may contribute to the further spread of the virus. Our study supports findings from a recent review, which concluded that face masks do not adversely affect hand hygiene [15].

The relationship between age and mask-wearing suggests that people generally wear masks to protect themselves, as mask-wearing was most common among those at the highest risk. This is understandable but may represent a failure of public health messaging. Cloth masks, which were worn by the majority of our respondents, are not completely effective at protecting the wearer, especially if they are in the vicinity of individuals not wearing masks. Therefore, protecting vulnerable patients solely by having them wear cloth masks will be less effective. Instead, masks should be worn by everyone to prevent spread by asymptomatic carriers. Since younger people are most likely to have asymptomatic infections, it is important that they wear masks. However, it may be difficult for people to think of themselves as a source of infection when they feel well. For example, a study of physicians found that hand washing was much more common when leaving a patient's room than when entering [16]. Replacing such natural tendencies for self-preservation with altruistic behaviors will likely require social pressure. Mask mandates could be helpful in that regard.

Study limitations include sampling from a population that has accessed the healthcare system in the past year and may be more aware of public health messaging. There may also be a non-response bias, as the survey was computer-based.

\section{Conclusions}

As the national conversation focuses on safe economic revival, it appears important to limit gatherings of more than 10 people and encourage mask-wearing. Essential activities and sanitization practices have not changed across time, and these practices are not affected by mask-wearing. Messaging should target younger patients, who are also least likely to wear masks. This may become increasingly important as colleges welcome students back to campuses, where social distancing may be harder to practice.

\section{Additional Information \\ Disclosures}

Human subjects: Consent was obtained by all participants in this study. Institutional Review Board of the Cleveland Clinic Foundation issued approval 20-438. This work was approved by the Institutional Review Board of the Cleveland Clinic Foundation. Animal subjects: All authors have confirmed that this study did not involve animal subjects or tissue. Conflicts of interest: In compliance with the ICMJE uniform disclosure form, all authors declare the following: Payment/services info: All authors have declared that no financial support was received from any organization for the submitted work. Financial relationships: All authors have declared that they have no financial relationships at present or within the previous three years with any organizations that might have an interest in the submitted work. Other relationships: All authors have declared that there are no other relationships or activities that could appear to have influenced the submitted work.

\section{Acknowledgements}

We would like to thank Gina Rupp, RN, MSN,and Oleg Lisheba for their assistance in data collection.

\section{References}

1. Fong MW, Gao H, Wong JY, Xiao J, Shiu EYC, Ryu S, Cowling BJ: Nonpharmaceutical measures for pandemic influenza in nonhealthcare settings-social distancing measures. Emerg Infect Dis. 2020, 26:976-984. 10.3201/eid2605.190995

2. Institution of Medicine: Modeling Community Containment for Pandemic Influenza: A Letter Report . The National Academies Press, Washington, DC; 2006. 10.17226/11800

3. Pan A, Liu L, Wang C, et al.: Association of Public Health interventions with the epidemiology of the COVID-19 outbreak in Wuhan, China. J Am Med Assoc. 2020, 323:1915-1923. 10.1001/jama.2020.6130

4. Lasry A, Kidder D, Hast M, et al.: Timing of community mitigation and changes in reported COVID-19 and community mobility - four U.S. metropolitan areas, February 26-April 1. MMWR Morb Mortal Weekly Rep. 2020, 69:451-457. 10.15585/mmwr.mm6915e2

5. Al-Hasan A, Yim D, Khuntia J: Citizens' adherence to COVID-19 mitigation recommendations by the government: a 3-country comparative evaluation using web-based cross-sectional survey data. J Med Internet Res. 2020, 22:8. 10.2196/20634

6. Schuchat A: Public Health Response to the Initiation and Spread of Pandemic COVID-19 in the United States, February 24-April 21. MMWR Morb Mortal Wkly Rep. 2020, 69:551-556. 10.15585/mmwr.mm6918e2

7. Coronavirus disease 2019 (COVID-19) in the U.S . (2020). Accessed: July 14, 2020: https://www.cdc.gov/coronavirus/2019-ncov/cases-updates/cases-in-us.html. 


\section{Cureus}

8. Speaker S, Doherty CM, Pfoh ER, et al.: Social behaviors associated with a positive COVID-19 test result [PREPRINT]. MedRxiv. 2020, 10.1101/2020.08.04.20168450

9. Hamilton CM, Strader LC, Pratt JG, et al.: The PhenX Toolkit: get the most from your measures . Am J Epidemiol. 2011, 174:253-260. 10.1093/aje/kwr193

10. Rubin GJ, Amlôt R, Page L, Wessely S: Public perceptions, anxiety, and behaviour change in relation to the swine flu outbreak: cross sectional telephone survey. BMJ. 2009, 339:b2651. 10.1136/bmj.b2651

11. Ohio Department of Health COVID-19 dashboard . (2020). Accessed: September 30, 2020: https://www.coronavirus.ohio.gov/wps/portal/gov/covid-19/dashboards/overview.

12. Sheehan MM, Pfoh ER, Speaker S, Rothberg MB: Changes in social behavior over time in the COVID-19 pandemic [PREPRINT]. MedRxiv. 2020, 10.1101/2020.08.27.20183376

13. Verity R, Okell LC, Dorigatti I, et al.: Estimates of the severity of coronavirus disease 2019: a model-based analysis. Lancet Infect Dis. 2020, 20:669-677. 10.1016/S1473-3099(20)30243-7

14. Food safety and coronavirus disease 2019 (COVID-19) . (2020). Accessed: June 22, 2020: https://www.cdc.gov/foodsafety/newsletter/food-safety-and-Coronavirus.html.

15. Mantzari E, Rubin GJ, Marteau TM: Is risk compensation threatening public health in the covid-19 pandemic?. BMJ. 2020, 370:m2913. 10.1136/bmj.m2913

16. Haessler S, Bhagavan A, Kleppel R, Hinchey K, Visintainer P: Getting doctors to clean their hands: lead the followers. BMJ Qual Saf. 2012, 21:499-502. 10.1136/bmjqs-2011-000396 